\title{
The bakari@ mentoring program: a framework for intervening with at-risk youth
}

\begin{abstract}
The current conceptual paper describes the purpose and foundation of the Bakari ${ }^{\circ}$ Mentoring Program, a culturally sensitive and gender specific prevention and intervention program for 14-17year old, at-risk, male and female adolescents. Given the program's mission, it aims to serve high school youth throughout San Luis Obispo County, California with the aim of assisting them in becoming socially conscious, responsible, and productive young men and women who successfully transition into adulthood while confronting life challenges in prosocial ways. Held on a college campus and supported by university departments and community partners, the Bakari ${ }^{\circ}$ Mentoring Program focuses on psycho-educational concepts and mastery of life skills and development. Discussion is focused on the history, foundation, structure, and outcomes of the program. In addition, preliminary outcome data is provided along with future directions for the program.
\end{abstract}

Keywords: adolescence, at-risk, mentoring, prevention, intervention
Volume 3 Issue 6 - 2015

\author{
Roslyn M Caldwell-Gunes,' Thomas A \\ Parham ${ }^{2}$ \\ 'Psychology and Child Development Department, California \\ Polytechnic State University, USA \\ ${ }^{2}$ University of California, Irvine, USA
}

\begin{abstract}
Correspondence: Roslyn M. Caldwell-Gunes, Department of Psychology and Child Development, California Polytechnic State University, I Grande Ave, San Luis Obispo, CA 93407, USA, Tel (805)756-2686, Email rmcaldwe@calpoly.edu
\end{abstract}

Received: October II, 2015 | Published: October 15, 2015

\section{Introduction}

Historically, the principal method in which society has facilitated positive development and preparation for the future of youth to become productive members of society has been founded upon education and opportunity that involves the home, school, and community. These areas of a child or adolescent's life have been perceived to create a tremendous amount of positive and negative outcomes in regard to the development of character among youth depending upon the type of relationship between these three entities. However, in recent decades adolescent youths' needs have been constantly changing, requiring increased support in helping them to recognize and understand their self- worth and importance as they move forward toward a productive future. Consequently, this effort requires cooperation of and support from the families, the schools, and the communities, with each assuming a major share of responsibility. One such program, the Bakari $^{\circ}$ Mentoring Program illustrates this cooperation through a culturally sensitive and gender specific intervention and prevention program for at-risk and underserved male and female youth ranging in age from 14-17 years. Derived from the Swahili language, the word Bakari ${ }^{\circ}$ means "One who will succeed"., ${ }^{1,2}$ The program is an outgrowth from the original Bakari ${ }^{\odot}$ Project created 20 years ago in Irvine, California, which was developed as a prevention and intervention model with the specific intention of anchoring educational initiatives in partnership with local organizations. The Bakari ${ }^{\odot}$ Mentoring Program's mission is to nurture socially conscious, responsible, and productive youth who can actualize their potential and take full advantage of life opportunities while confronting life challenges in pro-social ways. As such, the program aims to help youth successfully transition into adulthood.,

\section{Program overview}

The Bakari ${ }^{\odot}$ Mentoring Program is based upon three assumptions.

I. The first assumption is referred to as the meaning of manhood and womanhood. In other words, we live in a world where society grants young people privilege based on age, ultimately conferring adulthood status when youth reach either age 18 or 21. In other cultural traditions manhood and womanhood are not defined by age, but rather mastery of particular aspects of humanity or skills. Consequently, the relevant question we must ask youth has less to do with how old they are, and more to do with what skills they have mastered to certify them as adults. ${ }^{1,2}$

II. The second assumption focuses on the "Triangle for Success" and depends on a cooperative relationship between the home, school, and community. Educational achievement in communities has historically been facilitated by the collaboration of these three dimensions that, although continuing to exist, are becoming increasingly disconnected. This "disconnect" is represented by each dimension of the triangle blaming other dimensions for the failure of youth. The goal is to reconnect the triangle so that the home, school, and community are working in concert with one another to support youth.

III. The third assumption that guides the Bakari ${ }^{\circ}$ Mentoring Program is that the most daunting challenge facing the community and its youth are not drugs, gangs, violence, poverty, racism, or any other social ill, but rather the need for mental liberation. This assumption declares that youths' lives have been contaminated by intellectual, emotional, behavioral and spiritual shackles that conceptually incarcerate their thinking and limit their visions of possibility. ${ }^{1,2}$ The Bakari ${ }^{\odot}$ Mentoring Program seeks to release youth from these constraints and help them discover their potential by resocializing their behavior by resocializing their thinking, through intensive programming that fosters increased supervision and monitoring, and career and life skill development opportunities. ${ }^{1,2}$ The Bakari ${ }^{\circ}$ Mentoring Program seeks to prevent at-risk and underserved youth from a downward spiral that negatively impacts their educational progress, mental health and well-being, and decrease their vulnerability to engage in juvenile delinquency.

\section{Methods}

The overall structure of the 6-month manualized program ${ }^{3,4}$ with a 3-month follow-up phase (alternating male and female groups) is unique and consists of weekly three-hour psycho-educational sessions held on a college campus for youth participants, providing a positive experience and environment. Every 6 months, approximately 15 at-risk adolescents between the ages of 14-17years of age (high school youth) who are referred by local high schools are interviewed 
and accepted into the program based upon certain at-risk criteria that include: truancy, academic problems, behavioral problems at school and/or home, and/or any school related academic/behavioral contracts. Once accepted, youth are introduced to six areas of mastery that incorporate instructional and experiential intervention, which promotes educational and psychological development and re-socialization in order to facilitate progress toward responsible adulthood. The six core areas of mastery include: self-knowledge and self-awareness, history, relationships, skill development (i.e., anger management and conflict resolution, communication skills, career development, economic empowerment, health and wellness, and substance use/abuse), leadership, and community service. These components are facilitated by university (e.g., Career Services for career development) and community partners (e.g., Wells Fargo, Inc., for economic empowerment, and Creative Mediation for anger management and conflict resolution) who are considered experts in the field. It should be noted that each of the components are part of a manualized curriculum developed in order to maintain consistency and reliability in delivery of services. ${ }^{3,4}$

Additionally, weekly job readiness and professional development classes are provided along with occasional group community volunteer service activities, and tutoring, all of which are facilitated through program staff and community partners. Activities that facilitate prosocial behavior among youth are also infused throughout the program. (e.g., ropes team building courses, campus sporting events, camping trips). Parenting groups (both English speaking and bilingual/ bicultural groups) are also facilitated by a Licensed Clinical Social Worker and a translator. The program is also distinctive because weekly one-to-one and group mentoring is included and provided by college students from a diversity of majors, staff and faculty, and community volunteers. Additionally, an evaluative component is utilized and facilitated by a research team of students whereby youth and parents are assessed throughout the program across an array of psychological, educational, social, and emotional constructs. Recently, the Bakari ${ }^{\circ}$ Mentoring Program cultivated and implemented additional components that included job shadowing opportunities, and employment and job skills training to aid in the success of these at-risk youth transitioning into adulthood.

\section{Preliminary Outcomes}

The unique structure of the Bakari $^{\circ}$ Mentoring Program has demonstrated significant outcomes among the adolescent population because the manualized program employs targeted interventions that support the specific needs of youth while taking into consideration racial, ethnic, and gender differences. Since the inception of the Bakari ${ }^{\odot}$ Mentoring Program nearly eight years ago, the $\operatorname{Bakari} i^{\odot}$ Mentoring Program has consistently made an impact on the lives of over 135 youth (40\% Mexican American, 45\% White; 10\% Bi-racial; 3\% Asian American; and 2\% African American-which is consistent with the demographic backgrounds in this county) with an average program graduation rate of $80 \%$. Upon entry into the program, $90 \%$ of youth had issues related to truancy and by the end of the program, graduates showed $100 \%$ attendance along with significant improvement in academics and positive behavior in school. Additionally, $95 \%$ of youth at the start of the program had histories of school suspensions, contracts, and expulsions and by graduation, contracts were expunged and youth were able to make a "fresh start" in school with a $98 \%$ high school graduation rate (compared to an $81 \%$ national average). ${ }^{5}$ To date, $80 \%$ of the Bakari ${ }^{\circ}$ Mentoring Program graduates have entered the work force by age 18 . Of the youth who have graduated high school, $3 \%$ are attending 4 -year colleges, 30\% are attending 2 -year colleges, and $2 \%$ are serving in the military.

\section{Conclusion}

The Bakari $^{\circ}$ Mentoring Program is a very comprehensive, innovative, and evidence-based program that supports the notion that at-risk adolescents are in need of intensive psycho-educational programming, mentoring, and support, in order to successfully guide them to become productive citizens of society. Moreover, the program is unique and different than other health and human services programs and community based organizations on several levels: 1) its focus on specific skill areas that adolescents develop through a treatment prevention and intervention method created from a cultural frame of reference on a college campus setting; 2) one-to-one and group mentoring provided by both the college community and community partners and volunteers; 3 ) the opportunity for youth to acquire academic credit that undoubtedly benefits their school progress and redirect them toward pathways of success; and 4) the array of opportunities for youth to engage in prosocial and communal activities that allow them to internalize the notion that they are "visions of possibility".

The Bakari $^{\odot}$ Mentoring Program has been successful to date due to financial support from community agencies (e.g. County Board of Supervisors, Community Foundations, Wells Fargo, Inc., and the Sheriff's Office) and private donations, along with collaborative relationships with the university, community and school system, which reinforces the "Triangle for Success" assumption of the program. Moreover, the program is governed by an Advisory/ Executive Board that oversee the implementation of the program with members representing various agencies throughout the county including: Juvenile Justice and Delinquency Prevention; California State Assembly, District 35; County Office of Education, Wells Fargo, Inc., Latino Outreach Program; Superior Court; Literacy Council, County Community Foundation; the Children and Families Commission; and the University of California Cooperative Extension.

\section{Future Directions}

The Bakari ${ }^{\circ}$ Mentoring Program from a conceptual and preliminary standpoint has shown significant progress and can serve as a model intervention and prevention program for at-risk youth, both males and females nationwide. The current steps being taken in this direction is to analyze the pre and post measures regarding the progress and outcome of the youth and parents from a variety of domains mentioned previously. Subsequently, the program can be presented to various agencies throughout the country and provide training for implementation of services on a college campus.

Due to the dynamic needs of youth in general and the preliminary outcomes, in the near future, the program aims to solidify an additional piloted component that incorporates college and/or trade school skills in order to provide greater opportunities for this particular population of youth. Given the needs of at-risk youth, this content area will assist males and females in the development and strengthening of educational skills and knowledge; assisting in building cooperative relationships with colleges and trade schools; providing youth with an opportunity to gain valuable experience while learning about the college and trade school processes. Ultimately, this component will allow more youth the opportunity to successfully transition from high school to post-secondary or trade school education.

In conclusion, the Bakari ${ }^{\odot}$ Mentoring Program is an intensive community based program that focuses on social engineering that helps youth navigate their way through key elements of life. This has been confirmed by the Office of Juvenile Justice and Delinquency Prevention to be the most effective way to help at-risk youth achieve 
and maintain success. ${ }^{5,6}$ Moreover, the element of cultural awareness, sensitivity, competence, and proficiency which is at the center of the program is important for any program to incorporate given the dynamic factors of youth

\section{Acknowledgments}

None.

\section{Conflicts of interest}

Author declares there are no conflicts of interest.

\section{Funding}

None.

\section{References}

1. Parham TA, White JL, Ajamu A. The Psychology of Blacks (3rd edn), Prentice Hall, New Jersey, USA. 1999.
2. Parham TA, White JL, Ajamu A. The Psychology of Blacks (4th edn), Prentice Hall, New Jersey, USA. 2011.

3. Parham TA, Caldwell RM. The Bakari Project: Participant workbook. Kentay Productions, Los Angeles, California, USA. 2008.

4. Parham TA, Caldwell RM. The Bakari Project: Instructor manual. Kentay Productions, Los Angeles, California, USA. 2008.

5. Caldwell RM. Applications of an African Centered Psychology: The juvenile offender. In: Parham TA, et al. (Eds.), The Psychology of Blacks (4th edn), Prentice Hall, New Jersey, USA. 2011.

6. Chauhan P, McKitten R, Caldwell RM, et al. Reducing Disproportionate Minority Contact in the Juvenile and Criminal Justice. Symposium presentation at the annual meeting for the American Psychological Association, Washington DC, USA. 2014. 